\title{
Comparison between Sublingual and Vaginal Misoprostol for Induction of Labour in Primigravida
}

\author{
Sailaja Ghimire, Deepanjali Sharma, Samjhana Dhakal, Gehanath Baral \\ Department of Obstetrics and Gynecology, Paropakar Maternity and Women's Hospital, Thapathali, Nepal
}

Received: 1 July 2018; Accepted: 20 October 2018

DOI: 10.3126/njog.v13i3.23509

ABSTRACT

Aims: To compare the outcome and side effects of administration of sublingual misoprostol with vaginal misoprostol for induction of labour and cervical ripening.

Methods: It was a hospital based comparative study which was carried out in 120 patients in each group of sublingual and vaginal route of misoprostol induction from August 2016 to February 2017 at Paropakar Maternity and Women's Hospital, Thapathali, Kathmandu. Patients with Bishops score $<6$ were subjected for Misoprostol $25 \mu \mathrm{g}$ (for maximum 2 doses) 6 hours apart. Results were analyzed using SPSS 21 taking $\mathrm{p}$-value $\leq 0.05$ as statistically significant.

Results: The mean change in Bishops score after 6 hours of misoprostol was statistically significantly ( $p=0.001)$ in sublingual group in comparison to vaginal group. The difference in augmentation rate was not statistically significant $(\mathrm{p}=0.811)$. The mean time interval from drug administration to delivery was almost similar in both groups. The indications for cesarean section were similar in both the groups, the most common being fetal distress, $(67.33 \%$ in sublingual and $58.065 \%$ in vaginal group. In terms of maternal and neonatal outcome there was no difference.

Conclusions: Sublingual route results in significant changes of Bishop's score as compared to vaginal route. It was also significantly better in terms of fetal outcome. However, both routes appeared similar in terms of maternal outcome.

Keywords: induction of labour, misoprostol, sublingual route, vaginal route.

\section{INTRODUCTION}

Induction of labour implies stimulation of contractions before the spontaneous onset of labour, with or without ruptured membranes. When the cervix is closed and uneffaced, labour induction will often commence with cervical ripening, a process that generally employs prostaglandins to soften and open the cervix. ${ }^{1}$ Induction of labour occurs in 10$30 \%$ of the deliveries worldwide, lowest in Nigeria (1.4\%) and highest in Srilanka (35.5\%). ${ }^{2}$ Misoprostol, a prostaglandin E1 analogue, has been approved for ripening cervix and inducing labor in many countries. Misoprostol can be used orally, vaginally or sublingually. It is not suitable for parenteral use because of its rapid degradation in blood. ${ }^{3}$ Vaginal administration of misoprostol results in slower increase and lower peak plasma concentration of active metabolite than the oral administration, but overall exposure to the drug and duration of exposure is increased with vaginal administration. In addition

\section{CORRESPONDENCE}

Dr Sailaja Ghimire

Department of Obstetrics and Gynecology

Paropakar Maternity and Women's Hospital, Thapathali, Nepal

Email: sailaja.ghimir2002@gmail.com to the higher plasma levels, bioavailability was found to be greater in the sublingual than vaginal route.

\section{METHODS}

Total number of deliveries in six months from August 2016 to February 2017 was 9464 at Paropakar Maternity and Women's Hospital, Thapathali, Kathmandu; 120 cases each in sublingual and vaginal route of misoprostol induction were taken from antenatal OPD and ward. Inclusion criteria were primigravida, admitted for the induction of labour at 41-42 weeks of gestation with single live fetuswith cephalic presentation, Bishops scores less than 6andno contra-indication for vaginal delivery. Patients were then divided into 2 groups by lottery. Cardiotocogram was done prior to induction in all cases. Fetal heart sound (FHS) for $1 \mathrm{~min}$ and uterine contraction for 10 mins were recorded just before administration of drugs. Then patients were given $25 \mathrm{mcg}$ misoprostol either sublingually or vaginally. After 6 hours of first dose of misoprostol, vitals, uterine contraction and 
FHS were noted and bishops' score was assessed. Second dose was withheld in the presence of any of uterine contraction or fetal distress, spontaneous rupture of membrane and bishops score equal to six or more than six.

When labour set in, patient was augmented with injection oxytocin later; if in active phase then augmentation started immediately. Oxytocin was initially started with 2.5 units in $500 \mathrm{ml}$ of Ringer Lactate solution and started with a rate of 10 drops per minute and escalated $10 \mathrm{drops} / \mathrm{min}$ at an interval of 30 minutes up to maximum of 60 drops/minute. After the first bottle, in the second bottle, 5 units were placed in next bottle and started 30 drops /minute and escalated up to $60 \mathrm{drops} /$ minute and 5 units in next bottle was continued at $60 \mathrm{drops} /$ minute. If not delivered, re augmentation was started on next day with 5 units in $500 \mathrm{ml}$ of Ringer Lactate.

Bishop's score was the main outcome indicator. Secondary measures were interval from the start of induction to vaginal delivery, proportion of women who received oxytocin, induction to delivery time, mode of delivery, number of caesarean deliveries and maternal complications. Other outcome measures were Apgar score (at 5 minutes), NICU admission, neonatal death and incidence of meconium stained liquor. All mothers and babies were followed up daily until discharge. Mother were advised to inform on duty staffs if they noticed postpartum complications like fever, diarrhea, vomiting, excessive bleeding per vagina, pain in lower abdomen and neonatal complications. Data entry and analysis was then done with a help of the computer using SPSS 21 version. Research approval was taken and informed consent administered.

\section{RESULTS}

Total 240 cases of Primigravida of 41-42 weeks of gestation, attending ANC OPD and ANC ward, who met the selection criteria were enrolled after taking written informed consent .Majority of women were between 20-24 in either group, 78 (65\%) and 66 $(55 \%)$ in sublingual and vaginal group respectively. There was no significant difference in age between two groups (Table 1).

Table 1: Age group wise distribution $(\mathrm{n}=120)$.

\begin{tabular}{|c|c|c|c|}
\hline Age in years & Sublingual & Vaginal & p-value \\
\hline$\leq 19$ & $12(10 \%)$ & $19(15.8 \%)$ & \multirow{5}{*}{0.385} \\
\hline $20-24$ & $78(65 \%)$ & $66(55 \%)$ & \\
\hline $25-29$ & $24(20 \%)$ & $27(22.5 \%)$ & \\
\hline $30-34$ & $6(5 \%)$ & $8(6.7 \%)$ & \\
\hline Total & 120 & 120 & \\
\hline
\end{tabular}

The mean Bishops score pre induction and post induction with first dose of misoprostol after 6 hours were compared between two groups. Change in cervical score was significantly more in sublingual route $(\mathrm{p}=0.001)$ [Table 2].

Table 2: Bishops score before and after administration of drug.

\begin{tabular}{|l|l|l|l|}
\hline \multirow{2}{*}{ Bishops Score } & \multicolumn{2}{|c|}{ Mean \pm SD } & \multirow{2}{*}{$\begin{array}{l}\text { p- } \\
\text { value }\end{array}$} \\
\cline { 2 - 3 } & Sublingual & Vaginal & \\
\hline Initial Bishops & $4.09 \pm 0.87$ & $\begin{array}{l}4.18 \pm \\
\text { score }\end{array}$ & 0.812 \\
\hline $\begin{array}{l}\text { Bishops score after } \\
\text { 6 hours of 1st dose }\end{array}$ & $5.17 \pm 0.61$ & $4.68 \pm$ & 0.001 \\
\hline
\end{tabular}

Subsequent Oxytocin augmentation was done in 111 $(92.5 \%)$ cases in sublingual group and $110(91.7 \%)$ cases from vaginal group ( $\mathrm{p}=0.811)$. Induction to delivery interval was not statistically significant $(\mathrm{p}=0.605)$; the mean interval was $29.43 \pm 8.27 \mathrm{hr}$ in sublingual group and $29.2 \pm 8.527 \mathrm{hr}$ in vaginal group respectively (Table 3 ).

Table 3: Time interval from drug administration to delivery.

\begin{tabular}{|l|l|l|l|}
\hline $\begin{array}{l}\text { Time interval } \\
\text { (hrs) }\end{array}$ & Sublingual & Vaginal & p-value \\
\cline { 1 - 3 } $6-12$ & $2(1.6 \%)$ & $3(2.5 \%)$ & \\
\cline { 1 - 3 } $13-24$ & $47(39.2 \%)$ & $40(33.3 \%)$ & \multirow{2}{*}{0.605} \\
\cline { 1 - 3 }$>24$ & $71(59.2 \%)$ & $77(64.2 \%)$ & \\
\cline { 1 - 3 } Total & 120 & 120 & \\
\hline
\end{tabular}

Two- third of the cases underwent normal vaginal delivery and one- fourth had cesarean section in either group. However the results were not statistically significant (Table 4).

Table 4: Mode of delivery $(n=120)$.

\begin{tabular}{|c|c|c|c|c|}
\hline \multicolumn{2}{|c|}{ Mode Of Delivery } & Sublingual & Vaginal & p-value \\
\hline \multicolumn{2}{|c|}{ SVD } & $\begin{array}{l}79 \\
(65.8 \%)\end{array}$ & $\begin{array}{l}81 \\
(67.5 \%)\end{array}$ & \multirow{5}{*}{0.946} \\
\hline \multirow[t]{2}{*}{ Instrumental } & Vacuum & $7(5.8 \%)$ & $7(5.83 \%)$ & \\
\hline & Forceps & $2(1.7 \%)$ & $1(0.83 \%)$ & \\
\hline \multicolumn{2}{|l|}{ LSCS } & $\begin{array}{l}32 \\
(26.7 \%)\end{array}$ & $\begin{array}{l}31 \\
(25.83 \%)\end{array}$ & \\
\hline \multicolumn{2}{|l|}{ Total } & 120 & 120 & \\
\hline
\end{tabular}

Indications for Cesarean Section was similar in either group with one case of chorioamnionitis in vaginal group $(\mathrm{p}=0.86)$ [Figure 1]. 


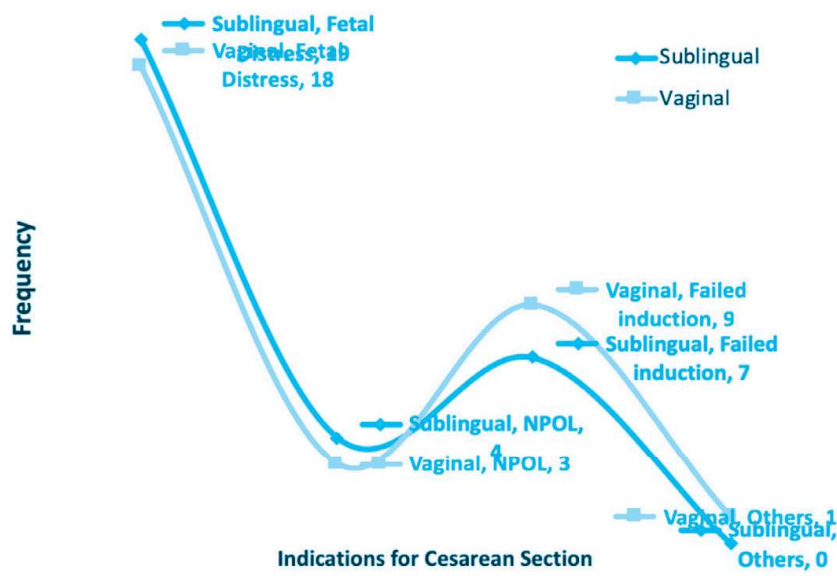

Figure 1: Indications for Cesarean Section.

There was statistically significant difference in Apgar score at 5 minutes $(\mathrm{p}=0.001)$ with more cases at low score in vaginal group, but the mean score was similar (Table 5).

Table-5: Apgar score at 5 minutes $(n=120)$.

\begin{tabular}{|c|c|c|c|}
\hline $\begin{array}{l}\text { Apgar } \\
\text { Score }\end{array}$ & Sublingual & Vaginal & p-value \\
\hline$<5$ & $3(2.5 \%)$ & $7(5.8 \%)$ & \multirow{3}{*}{0.001} \\
\hline $5-6$ & $7(5.8 \%)$ & $6(5 \%)$ & \\
\hline$\geq 7$ & $110(91.7 \%)$ & $107(89.2 \%)$ & \\
\hline Mean \pm SD & $7.61 \pm 0.792$ & $7.6 \pm 0.92$ & 0.94 \\
\hline
\end{tabular}

Neonatal outcomes were also compared in terms of NICU admission ( 11 vs. $16, p=0.307$ ) and neonatal death ( 3 vs. $5, p=0.472$ ) in sublingual vs. vaginal group. Meconium stained amniotic fluid was found more in vaginal route of drug but it was not statistically significant $(\mathrm{p}=0.231)$ [Figure-2].

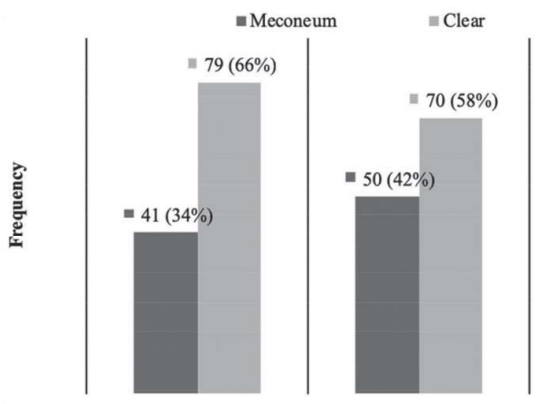

Figure-2: Color of amniotic fluid by route of administration of drug

Figure 2: Color of amniotic fluid by route of administration of drug. There were insignificant side effects of drug in either group.

\section{DISCUSSION}

Sometimes it is necessary to bring on labour artificially because of safety concerns for the mother or child. The procedure may be performed for medical reasons or on request by the woman (elective induction). Metaanalysis has been carried out to compare the effects of the different doses of misoprostol administered vaginally, orally and sublingually and have suggested that there are no statistically significant differences with respect to the efficacy of the different routes of administration.4 Its off-label indication for labour induction has been endorsed by the American College of Obstetricians and Gynecologists and Royal College of Obstetrician and Gynaecologists. 5 The aim of our study was to assess patient satisfaction with two routes of administration of misoprostol for labour induction in postdated pregnancies in terms of maternal and fetal outcome.

The criteria for inclusion being primigravida, age group distribution in our study showed majority of women were between 20-24 in both groups, 78 (65\%) in sublingual and $66(55 \%)$ in vaginal (Table 1$)$. Sedigheh et al included $24.65 \pm 4.42$ and $24.34 \pm 4.05$ age group in sublingual and vaginal group respectively and all were primigravida similar to our study. ${ }^{6}$

The mean Bishops score pre induction and post induction with first dose of misoprostol after 6 hours were compared between two groups. Change in cervical score was significantly more in sublingual route $(\mathrm{p}=0.001$, Table 2$)$. In study reported by Sedigheh et al, the changes in Bishops score were studied after four hours, which showed $3.7 \pm 2.4$ and $4.1 \pm 2.1$ in sublingual and vaginal groups. However, 
the dosage in vaginal group was $50 \mu \mathrm{g}$ and $25 \mu \mathrm{g}$ in sublingual group. ${ }^{6}$

Induction to delivery interval was not statistically significant $(\mathrm{p}=0.605)$; the mean interval was 29.43 $\pm 8.27 \mathrm{hr}$ in sublingual group and $29.2 \pm 8.527 \mathrm{hr}$ in vaginal group respectively (Table-3). A randomized, triple blind, placebo controlled trial done by Bahia et al, showed similar results as our study. The mean time interval between misoprostol commencement and delivery was $497.10 \pm 291.49$ and $511.67 \pm 08.46$ minutes for the sublingual and vaginal groups. ${ }^{7}$

Two-third of the cases underwent normal vaginal delivery and one-fourth had Cesarean Section in either group. However, the results were not statistically significant ( $p=0.46$, Table-4). Nassar et al8 showed similar results as our study. There were 50 (58.8\%) and $49(57.7 \%)$ vaginal deliveries in sublingual and vaginal group respectively with no statistical difference in their study $(\mathrm{p}=1)$.

The main indication for caesarean section in our study was foetal distress in both the groups, 19 (63.33\%) vs. $18(58.06 \%)$ followed by failed induction as commonest indication. There were 7 (23.33\%) cases of failed induction in sublingual group as compared to $9(29.03 \%)$ in vaginal group. Other indications included non-progress of labour and chorioamnionitis. According to study of Bartusevius et al9, fetal distress was the most common indication of caesarean section in both groups, $12(17 \%)$ versus $14(20 \%)$ in sublingual and vaginal group respectively.

Our study compared the neonatal outcomes in terms of Apgar score at 5 minutes, NICU admission, NND and meconium stained liquor. Apgar score was better in sublingual group as compared to vaginal group in respect to statistical significance when it was compared intervals of $<5,5-6$ and $>7$. However, the mean APGAR score at 5 mins in sublingual and vaginal groups were $7.61 \pm 0.792$ and $7.6 \pm 0.92$. There were $11(9.2 \%)$ versus $16(13.3 \%)$ admission from sublingual and vaginal group respectively. Three neonatal deaths occurred in sublingual group whereas five occurred in vaginal groups.
In the study reported by Feitosa et al, neonatal outcome was better as only $1 \%$ of babies required admission in both vaginal and sublingual group and only $3 \%$ of babies had Apgar score $<7$ at five minutes in vaginal group and none in sublingual group.10 Similar figure was seen in the study of Zahran et al as $1.6 \%$ of babies required admission in sublingual group and $2.1 \%$ in vaginal group. Only $0.8 \%$ of babies had Apgar score $<7$ at five minutes in sublingual group and $1.6 \%$ in vaginal group in this study. These findings suggest that sublingual route is better for neonatal prospective than vaginal route but large sample size is required to see any statistically significant difference. ${ }^{11}$

Meconium stained amniotic fluid was found more in vaginal route of drug though it was not statistically significant in our study $(\mathrm{p}=0.231)$ [Figure 2]. This may be explained by the fact that the direct effect of misoprostol on the cervix when given through vaginal route contribute to excessive uterine activity, FHR abnormalities and higher rate of meconium stained liquor.10 However more data's are required to prove it.

Maternal side effects were not much noticed in our study, which might be due to low dosage of misoprostol. Studies done by Bartusevicius et al also did not so any significant maternal side effects. 9

\section{CONCLUSIONS}

Sublingual route of misoprostol had better effect on cervical ripening compared to vaginal route. The mean induction to delivery, when compared between both the groups, was not statistically significant. The commonest mode of delivery in both the groups was Normal vaginal delivery. The most common indication for caesarean section in both the groups was found to be foetal distress. However, meconium stained liquor were found higher in vaginal group comparatively to sublingual group. The Apgar score at five minutes was significantly better in sublingual group. The intrapartum maternal side effects were few in both the groups and it was not statistically significant. 


\section{REFERENCES}

1. Cunningham FG, Leveno KJ, Bloom SL, Spong CY, Dashe JS, Hoffman BL et al. Williams Obstetrics.24th edition. New York: McGraw Hill Education; 2014.Chapter 26, Induction and Augmentation of labor;500-08

2. Department of Reproductive Health and Research. WHO recommendations for induction of labour.Geneva.WHO,2011.

3. Giacalone PL, Targosz V, Laffargue F, Boog G, Faure JM Cervical Ripening With Mifepristone before Labour Induction A Randomised Study. ObstetGynecol 1998;92:487-92.

4. Rijal PR, Regmi MC. Agrawal A, Uprety D, Katwal B Indications for induction of labour : A prospective Analysis Nepjol, 2010;8(2):114-6.

5. Fernando A, Shirish ND, Amarnath GB. Practical guide to high risk pregnancy and delivery. 3rd edition. New Delhi Elsevier, 2008.Chapter11,Prolonged pregnancy; p.284-86.

6. Jaana N, Arora A, Biswas SC. Misoprostol in cervical ripening and inductionof labour.In: Barik S, Dutta S, Gupta K editors Misoprostol in obstetrics and Gynaecology. Newdelhi: Jaypee brothers,2000.p.70-80

7. Carlan SJ, Boldin S, Blust D, O'Berein WF. Safety and efficacy of misoprostol orally and vaginally: A randomized trial. Obstet Gynecol. 2001;98:107-12

8. Gupta K, Chowdhary B. Misoprostol: Induction In: Barik $\mathrm{S}$, Duttas, Gupta k editors. Misoprostol in obstetrics and gynaecology. New Delhi: Jaypee Brothers,2005.p.1-7.

9. Shetty A, Mackle L, Danielian P, Rice P, Templeton A Sublingual misoprostol for induction of labour at term: A randomized controlled trial. BJOG. 2002;109(6):645-50.

10. Lumbiganon P, Hofmeyr J, Gulmezoglu AM, Pinol A, Vellon $\mathrm{J}$. Misoprostol dose related shivering and pyrexia in the third stage of Labour. WHO collaborative trial of misoprostol in management of third stage of labor. BJOG.1999;106: 304-8

11. American College of Obstetrics and Gynecology committee opinion. New US Food and Drug administration labeling on Cytotec use and pregnancy: 2003;283.
12. Nassar AH, Awwad J, Khalil AM, Abu-Musa A, Mehio G, Usta IM. A randomized comparision of patient satisfaction with vaginal and sublingual misoprostol for induction of labour at term. BJOG. 2007;114:1215-21.

13. Sanchez- Ramos L, Danner CJ, Delke I, Kaunitz AM The effect of tablet moistening on labour induction with intravaginal Misoprostol: A randomized trial. Obstet Gynaecol. 2002;99(6):1080-4.

14. Beigi A, Kabiri M, Zarrinkoub F. Cervical ripening with misoprostol at term. International $\mathrm{J}$ of Obst Gynaecol. 2003:83:251-5.

15. Ayati S, Vahidroodsari F, Farshidi F, Shahabian M, Aghaee MA Vaginal Versus sublingual Misoprostol for labor induction at term and post term: a Randomized Prospective study. Iranian Journal of Pharmaceutical Research. 2014;13(1):299-304

16. Jahromi BN, Poorgholam F, Yousefi G, Salarian L. Sublingua versus Vaginal Misoprostol for the Induction of labor at Term: A Randomized, Triple- Blind, Placebo- controlled clinical Trial. Iran J Med Sci. 2016;41(2):79-85.

17. Bartusevicius A, Barcaite E, Krikstolaitis R, Gintautas $\mathrm{V}$, Nadisauskiene R. Sublingual compared with vaginal misoprostol for labour induction at term: a randomized controlled trial. BJOG. 2006;113:1431-7.

18. Souza A, Amorim M, Feitosa F. Comparision of sublingual versus vaginal misoprostol for induction of labour: a systemic review. BJOG. 2008;115:1340-9.

19. Zahran MK, Shahin AY, Abdellah MS, Elsayh A. Sublingual versus vaginal misoprostol for induction of labor at term: A randomized prospective placebo-controlled study. Journal of Obstetrics and Gynaecology Research. 2009;35:1054-60

20. Alfirevic Z, Weeks A. Oral misoprostol for induction of labour. Cochrane Database of Systematic reviews. In: The Cochrane library, Issue 3, 2009 Art. No. CD001338. 